\title{
OS NOVOS LETRAMENTOS DIGITAIS COMO LUGARES DE CONSTRUÇÃO DE ATIVISMO POLÍTICO SOBRE SEXUALIDADE E GÊNERO
}

\author{
THE NEW DIGITAL LITERACIES AS SITES FOR THE CONSTRUCTION OF \\ POLITICALACTIVISM ABOUT SEXUALITY AND GENDER
}

\author{
LUIZ PAULO DA MOITA LOPES ${ }^{* * *}$
}

\begin{abstract}
"Os trastes, artefatos e máquinas que nossa cultura confecciona e elabora sem cessar veiculam relações de poder e autoridade em torno das quais se organizam as práticas sociais cotidianas. Não há usos políticos da tecnologia, já que, parafraseando desta vez o feminismo, "o técnico é político"" (Sádaba \& Gordo, 2008: 11).
\end{abstract}

\begin{abstract}
RESUMO: Compreendendo os chamados novos letramentos digitais como práticas socioculturais, argumentase como tais espaços se tornaram, na contemporaneidade, lugares de ativismo político e de construção de significados transgressores sobre a vida pública e privada, por meio dos quais sub-políticas são construídas. A seguir, teoriza-se a vida social em tais letramentos como típica da Web 2.0 no sentido de que envolve modos de ação e de pensar específicos, que questionam a autoria, já que são coloborativos e participativos, ao passo que nos colocam em meio a Multidão e seus discursos inovadores, desestruturadores e inesperados. Tais discursos são cruciais, pois podem colaborar na reinvenção social, ensaiando o futuro. Para finalizar, analisam-se dois espaços de afinidades na Web 2.0, centrados no ativismo político sobre sexualidade e gênero, caracterizando os movimentos interacionais em desenvolvimento em tais práticas sociais de letramentos e o modo como nos expõem a futuros alternativos: uma demanda crucial em nossos tempos. Palavras-chaves: letramentos digitais; Web 2.0; Multidão; ativismo político; gênero; sexualidade.
\end{abstract}

\begin{abstract}
Theorizing the so-called new digital literacies as socio-cultural practices, it is argued that such sites have contemporarily become spaces for political activism and for the construction of transgressive meanings about public and private life, through which sub-political actions are constructed. Next, social life in such literacies is theorized as typical of Web 2.0 in the sense that it involves specific modes of action and of thinking, which question authorship, since they are collaborative and participative, at the same time that they position us amidst the Multitude and their innovative, de-structured and unexpected discourses. Such discourses are crucial because they may collaborate with the re-invention of social life, rehearsing the future. Finally, two spaces of affinity in Web 2.0, centered on sexuality and gender, are analyzed through the characterization of the interactional moves in such social practices and through the way they expose ourselves to alternative futures: a crucial demand of our times.
\end{abstract}

Keywords: digital literacies; Web 2.0; Multitude; political activism; gender; sexuality

* UFRJ, Rio de Janeiro (RJ). Brasil. <moitalopes@ pq.cnpq.br>

** Sou grato ao CNPq pela Bolsa de Produtividade em Pesquisa que possibilitou a investigação aqui relatada (CNPq 303301/2009-0). 


\section{INTRODUÇÃO}

Se a praça pública tem tradicionalmente sido usada como o lugar em que a vida política, desde a antiguidade clássica - a ágora grega -, era o local na cidade onde as pessoas se reuniam para as decisões fundamentais da cidadania, gerando a vida democrática, ou se os moinhos da Idade Média, e mesmo no século XVI (Ginzburg, 1976/1987) possibilitavam igualmente a reunião das pessoas e a construção de alternativas para a vida social longe do olhar de vigilância e de punição da Igreja (Cleminson \& Gordo, 2008), os novos letramentos digitais, disponibilizados na web 2.0, se tornaram a praça pública e os moinhos nos quais a vida pública assim como a privada (em um mundo no qual não há muita diferença entre o privado e o público) estão continuamente em discussão, muitas vezes igualmente distantes dos olhares institucionais ou no anonimato.

O relato de Ginzburg (1976/1987) sobre um moleiro, a que já me referi em Moita Lopes (no prelo), cujas palavras são recuperadas dos Autos da Inquisição, bem ilustram o que Cleminson \& Gordo (2008: 32) indicam sobre os moinhos medievais como lugares de transgressão que rivalizavam com a igreja ao atrair "multidões, como lugar para facilitar a fofoca e o fluxo da informação, urdir rebeliões e disseminar novas técnicas" (:38) e para favorecer "novos intercâmbios técnicos, sexuais e culturais" (: 36). Os moinhos tinham, desse modo, a função de reinventar a vida social e política. Ou, nas palavras do próprio moleiro, respondendo ao tribunal da Inquisição, na posição do que talvez possamos compreender hoje como na de um ativista político:

\footnotetext{
"Papas, cardeais e padres 'arruínam os pobres': mas em nome do quê? Com que direitos? O papa é 'homem como nós', com a diferença de que tem poder (pode fazer) e, portanto, mais 'dignidade'. Não existe diferença alguma entre clérigos e leigos: o sacramento da ordenação é uma 'mercadoria'. Assim como todos os outros sacramentos e leis da igreja: 'mercadorias', 'invenções', e graças a elas os padres engordam” (Ginzburg, 1976/1987: 58).

Ou, ainda: "meu espírito era elevado e desejava que existisse um mundo novo e um novo modo de viver, pois a Igreja não vai bem e não deveria ter tanta pompa" (Ginzburg, 1976/ 1987: 52).
}

O argumento principal subjacente a este artigo é, por um lado, que os novos letramentos digitais na Web 2.0 podem ser vistos como tendo o mesmo caráter apontado acima em relação à agora e aos moinhos medievais, como lugares de debates políticos sobre a vida pública e privada, e especialmente de ativismo político do qual podemos participar sem sair de casa; e, por outro, que tais letramentos permitem que nos libertemos "dos constrangimentos do passado" (Giddens, 2000: 56) ao questionarem muitos dos significados tradicionais que pautaram nossas histórias de vida. É dessa forma que a possibilidade de acesso a uma profusão de discursos nos quais circulamos hoje na Internet provoca vertigens naqueles que operam com base em roteiros de vida bem sedimentados (Fridman, 2000 e Fabrício \& Moita Lopes, 2004). Além disso, a natureza do ethos colaborativo e participativo da Web 2.0 (Moita Lopes, no prelo), nos novos letramentos digitais, pode ser compreendida como espaço de discussão, de reinvenção social, de agenciamento e de transgressão. É assim que “... o ciberespaço permite trazer ao primeiro plano a natureza profundamente social e material das tecnologias, deixando por sua vez à margem os determinismos tecnológicos ou os essencialismos sociais" (Mayans i Planells, 2008: 119). 
Essa característica da tecnologia como uma prática de ação sociopolítica é ainda estranha para muitos que entendem que a técnica é essencialmente neutra, tendo a ver, no caso da tecnologia da informação, somente com aprender a usar programas de computação, manejar várias mídias convergentes na tela do computador, transferir arquivos de lá para cá etc., separadamente de nossos desejos e sonhos sociais e políticos como se a técnica existisse em separado de quem somos como seres sociopolíticos. Essa posição só é possível se esquecermos das palavras de Santos (2000) quando afirma que, quando a técnica muda, estamos diante de um novo mundo e de seus desafios para nossas vidas. Segundo Sádaba e Gordo (2008: 9), "se recuperou, somente nas últimas duas ou três décadas, um discurso sobre a tecnologia que reivindica sua natureza política e seu vínculo íntimo com a organização social em graus diferentes". Da mesma forma que a tecnologia impregna as atividades sociais, ela também faz com que as ações políticas requisitem a tecnologia como lugar de provocar mudanças sociais ou de, minimamente, fazer repensar a vida social (Sádaba \& Gordo, 2008).

Especialmente, no campo da Lingüística Aplicada, i.e., dos estudos que estão sendo feitos no campo de ensino de línguas por computador na escola e em relação aos usos da tecnologia em outras práticas sociais, esta é uma intravisão importante uma vez que o apagamento dos sujeitos sociais e de suas histórias sociopolíticas e corpóreas continua a guiar muito da pesquisa neste campo (Moita Lopes, 2008), tornando a tecnologia por si mesma um fetiche em separado de questões sociopolíticas e discursivas. Na verdade, esse continua a ser um problema no campo da Lingüística Aplicada, em geral: uma questão com a qual a chamada Lingüística Aplicada Indisciplinar (Moita Lopes, 2008) tenta lidar.

Além disso, o fato de que os novos letramentos digitais serem lugares em que as relações sociais são potencializadas infinitamente nos convida a co-participar da vida de pessoas que não conhecemos, que desarticulam nossas concepções de mundo e ideologias, e que multiplicam os discursos a que temos acesso de forma ilimitada. Tal característica possibilita dizer que na Internet, seguindo Hardt \& Negri (2005), nos deparamos com o que teoricamente esses autores definem como Multidão, a qual

"é composta de inúmeras diferenças internas que nunca poderão ser reduzidas a uma unidade
ou identidade única - diferentes culturas, raças, etnias, gêneros e orientações sexuais; diferentes
formas de trabalho; diferentes maneiras de viver; diferentes visões de mundo; e diferentes
desejos" (: 12),

Assim, a Internet

"é uma rede distributiva [o que] constitui uma boa imagem de base ou modelo para [o conceito teórico de] multidão, pois, em primeiro lugar, os vários pontos nodais se mantêm diferentes mas estão todos conectados na rede, e além disso as fronteiras externas da rede são de tal forma abertas que novos pontos nodais e novas relações podem estar sendo constantemente acrescentados" (: 140).

Diferentemente de pensar em massas, nas quais as diferenças se dispersam ou são apagadas (Hardt \& Negri, 2005), o conceito de Multidão contrariamente implica o acirramento da diferença e da alteridade e uma gama de possibilidades para a vida social e de discursos que a constroem ou a transformam de uma forma nunca experimentada antes. Envolve 
assim uma concepção bem diferente das comunidades nas praças públicas, nos moinhos e na sociedade de massas uma vez que nas redes sociais na Internet há uma exacerbação semiótica ou hipersemiotização e uma multiplicidade de performances identitárias. Essa posição implica compreender que não são só as grandes empresas, as instituições (mídia, governo, educação etc.) e o capital que se acercaram da tecnologia, mas que as pessoas podem fazer uso dela para se reinventarem ou para recriarem as práticas sociais nas quais vivem, vinculando-se ou não a movimentos sociais. Nas palavras de Sádaba \& Gordo (2008: 11), isso significa dizer que "rompemos, portanto, com a representação de uma tecnologia a serviço unicamente dos donos do mundo (algo inegável, mas não exclusivo) e assumimos uma certa ambivalência política da mesma".

As lanhouses superlotadas nas periferias brasileiras dão um testemunho flagrante de tal ambivalência, uma vez que em tais espaços se pode experimentar performances identitárias inovadoras e participar de movimentos sociais e, portanto, de ações sociopolíticas, ainda que os participantes estejam situados nas margens sociais. Não teriam também as lanhouses semelhanças com o papel que os moinhos exerciam no passado como lugares de acesso a possibilidades de transgredir significados compreendidos como legítimos, agora, porém, com acesso aos discursos da Multidão? É nessa direção que Guimarães (2009), em sua etnografia em uma lanhouse, mostra as práticas sociopolíticas relativas à reinvenção do gênero e da sexualidade ${ }^{1}$ em desenvolvimento nesse contexto na periferia da cidade do Rio de Janeiro, salientando como os jovens na lanhouse estudada deixam claro como ali podem viver vidas que não são facilmente experimentadas no contexto da família e em outras instituições. Nas palavras de Mayans i Plannels (2008: 118), trata-se de entender que "o ciberespaço não [é] monopolizado, daí a capacidade de agência e de construção estar estendida a todo mundo".

Além de funcionarem como lugar de acesso às redes sociais e aos discursos que nela circulam para quem não tem computador em casa, as lanhouses têm também o papel de possibilitar espaço para transgredir significados cristalizados longe da vigilância da vida institucional (da família, por exemplo, no caso dos jovens): um lugar de construir contranarrativas. Isso implica dizer que

\footnotetext{
"não se pode mais considerar unicamente o campo técnico como um mero instrumento de controle e de dominação mas também como um objeto reciclável, moldável e de construção por meio de outros espaços do social cujas orientações são heterogêneas e cujas consequências são ainda imprevisíveis (e merecem ser exploradas em profundidade) (Sádaba \& Gordo, 2008: 12).
}

Na primeira parte do trabalho, discuto os novos letramentos digitais de uma perspectiva sociocultural e os ganhos epistêmicos de tal enfoque teórico para esta investigação. A seguir, caracterizo a Web 1.0 e a Web 2.0 como dois tipos diferentes de mindset ou de modos de pensar e conhecer por meio dos quais o mundo é vivido na Internet (Lankshear

${ }^{1}$ Sigo a visão de que o gênero e a sexualidade são performativos (Butler, 1990), o que implica dizer que não existe nenhuma essência do gênero e da sexualidade, que pre-exista à performance no aqui e no agora. O gênero e a sexualidade são efeitos de significados de nossas ações. Somos o que somos por causa do que fazemos; não somos a causa do que fazemos (Moita Lopes e Fabrício, 2007; Moita Lopes, 2008; Fabrício \& Moita Lopes, 2010). 
\& Knobel, 2008: 31). Para finalmente, discutir o ativismo político dentro dos movimentos sociais na Web 2.0 como forma de transgressão. Ao concluir, analiso dois espaços de afinidades $^{2}$ (um blog e uma página no orkut) de ativismo político como um tipo de novo letramento digital, caracterizando o que conta como letramento em tal prática por meio da análise da interação em desenvolvimento ali.

\section{OS NOVOS LETRAMENTOS DIGITAIS COMO PRÁTICAS SOCIOCULTURAIS}

Os estudos dos letramentos como práticas sociais situadas têm avançado continuamente. Tais avanços são perceptíveis desde os trabalhos pioneiros de Brice Heath (1983) e Street (1984) e da coletânea organizada por Kleiman (1995), no Brasil, que chamaram atenção para os letramentos como ações sociais situadas, nos quais os participantes operam na construção do significado, com base em como entendem localmente o que conta como letramento, até compreensões dos letramentos que salientam os discursos que constroem nossas identidades sociais assim como a vida social em tais práticas (Gee, 1996; Moita Lopes, 2002 e 2005, por exemplo). Em tal percurso, a pesquisa deslocou o foco de aspectos decodificativos e psicológicos da leitura/escrita para compreender os letramentos por meio de lentes etnográficas (Brice Heath \& Street, 2008), investigando-os e entendendo-os como lugares de ação social "em contextos de práticas sociais, culturais, políticas, econômicas, que os constituem e dos quais são constitutivos" (Lankshear \& Knobel, 2007: 1). Desse modo, pode-se dizer que, embora a leitura tenha sido tradicionalmente compreendida do ponto de vista psicológico, o conceito de letramento, por outro lado, tem um cunho sociológico e antropológico e está sempre relacionado a um sentido de identidade social que os participantes das práticas encenam ao construir a vida social (Lankshear \& Knobel, 2008: 12).

É assim que passou a ser possível a compreensão de que se pode fotografar os letramentos (http://www.literacy.lancs.ac.uk/resources/images.htm): uma perspectiva que abandona uma visão restrita dos letramentos, voltados unicamente para o que os olhos e o cérebro fazem ao percorrer a página escrita. Essa tradição constitui o que se entende como os novos estudos dos letramentos (Gee, 1996), que os compreende como sempre encaixados em práticas sociais, culturais e históricas mais amplas, o que impossibilita pensarmos em letramento, mas ao contrário em letramentos uma vez que variam na dependência de como os participantes entendem o que está ocorrendo nas práticas com base em quem são, suas histórias e nos contextos macro sócio-histórico-culturais em que estão situados.

Muitos desses estudos (Maybin \& Moss, 1993; Moita Lopes, 2005, por exemplo), seguindo uma compreensão sociocultural de base vygotskiana, chamaram a atenção para a oralidade como instrumento crucial de mediação na construção do significado em tais práticas: uma contribuição que tornou a análise do discurso oral central para estudar os

${ }^{2}$ Espaços de afinidades é um conceito usado por Gee (2004: 85) para se referir a como em tais espaços "as pessoas se relacionam umas com as outras, primariamente em razão de interesses, esforços, objetivos, ou práticas comuns". ... "Ativistas sociais, independentemente de suas causas serem ecologia, anti-globalização ou vales escolares, também frequentemente se organizam em termos de espaços de afinidades" (: 87). 
letramentos, já que é por meio da oralidade que os significados são construídos, negociados, contestados e disputados pelos participantes. Note-se, porém, que nos espaços de afinidades na web 2.0, aqui estudados, é o discurso escrito (ou conversa escrita entremeada por imagens, fotos, emoticons etc. que é a ferramenta de mediação para a construção de significado). Além disso, mais recentemente, os estudos dos letramentos passaram a incluir práticas sociais outras que aquelas voltadas unicamente para o texto escrito, abarcando concepções mais amplas dos letramentos como quaisquer práticas de construção de sentido: letramentos radiofônicos, televisivos, digitais, no mundo do trabalho etc. Essa visão, inspirada no trabalho de Paulo Freire no qual ler é ler o mundo e no conceito de multiletramentos (Cope \& Kalantzis, 2000), desenvolvido pelo que ficou conhecido como o Grupo de Nova Londres", baseia-se na concepção de que "texto [é] essencialmente qualquer coisa por meio da qual se pode construir sentidos" (Lewis, Enciso \& Moje, 2007: xvii).

Os textos no mundo dos multiletramentos em que estamos vivendo passaram a ser construídos de formas inovadoras nas telas dos computadores, nos quais convergem no desktop do computador, ao se apertar uma tecla, ferramentas complexas, que são facilmente acessíveis tais como aquelas que possibilitam operar simultaneamente com imagens, sons, músicas, cores, vídeos, textos escritos etc. em hipertextos planejados como lugar de construção de sentido em um mundo no qual o conceito de design/ planejamento se tornou central (Kress \& Van Leeuwen, 2001 e Kress, 2003).

Mas como entender os novos letramentos digitais como práticas sociais situadas? Justamente por que tais letramentos envolvem a participação colaborativa de atores sociais localizados socio-histórico-culturalmente na construção conjunta de significados, mediada por instrumentos multisemióticos (textos, imagens, vídeos, sons etc.), em comunidades de práticas (Wenger, 1998) no mundo digital. A tela do computador deixa de ser somente um local onde se busca informação e passa a ser principalmente um lugar de construção, de disputa, de contestação de significados. Ou seja, passa a ser um espaço de encontros múltiplos com outros atores sociais, aumentando e transformando nossos repertórios de sentidos infinitamente, uma vez que, como apontei acima, as relações em tais práticas ocorrem no âmbito do que Hardt \& Negri (2005) chamaram de Multidão.

Os ganhos epistêmicos de tal enfoque estão relacionados, portanto, à possibilidade de compreender os novos letramentos digitais como práticas sociais nas quais atores operam ou agem em um ethos colaborativo e participativo na construção de significados (Moita Lopes, no prelo), reconhecendo socialmente tais operações / ações como um modo de fazer coisas no mundo (Lankshear \& Knobel, 2007: 4). Essa é uma distinção crucial, posto que possibilita teoricamente a compreensão dos novos letramentos digitais como lugares de ativismo político ou de transgredir significados cristalizados, aumentando infinitamente os modos e lugares de ação sociopolítica na vida social. Implícito está aqui a ideia de que a Internet amplia as possibilidades de relacionamentos sociais para além dos horizontes tradicionais (do mundo da família, da escola, dos amigos etc.), nos colocando de forma dramática frente a frente com a alteridade e com a politização da vida social..

${ }^{3} \mathrm{O}$ grupo de Nova Londres (uma pequena cidade no estado de New Hampshire nos Estados Unidos) é como ficou conhecida a reunião de pesquisadores, em sua maioria do mundo anglo-saxônico, durante uma semana em 1994, para discutir a questão do futuro do ensino dos letramentos à luz das mudanças vertiginosas que o mundo estava e está enfrentando. Tal reunião resultou no volume editado por Cope \& Katantziz (2000). 


\section{VIVENDO NA WEB 1.0 E NA WEB 2.0}

O que interessa nessa dicotomia entre Web 1.0 e Web 2.0 para este trabalho se refere justamente a como as práticas sociais dos letramentos digitais foram alteradas, passando a constituir o que se chama de novos letramentos digitais e, principalmente, os ganhos dessa mudança da Web 1.0 para a Web 2.0, de modo a compreender o ativismo político nas práticas da Web 2.0 dos pontos de vista pragmático e epistemológico O mundo da Web 1.0 pode ser entendido como aquele no qual a tela do computador era um lugar de consumo ou a ser consumido pelo usuário. Como um texto a ser lido, o hipertexto oferecia / oferece roteiros a serem seguidos por quem escolhe navegá-lo. Como apontam Lankshear \& Knobel (2007: 17), "a primeira geração da Web tem muito em comum como uma abordagem 'industrial' em relação à atividade produtiva material. Companhias e produtores operavam para produzir artefatos para o consumo. Havia uma grande divisão entre consumidor e produtor".

Tal material a ser consumido repetia o padrão da página do livro escrita pelo especialista, que decidia o que deveria ser lido e, na verdade, o como, embora no hipertexto os caminhos da navegação pelo usuário sejam escolhidos por ele mesmo (o que não quer dizer que no livro o leitor não possa fazer o mesmo). Mas persistia a autoridade do autor como especialista. Assim, o usuário era um consumidor do que a página na Web disponibilizava. De fato, tratava-se de um usuário de um produto publicado por alguém posicionado em um lugar de autoridade: o autor. A lógica sob a qual o usuário operava era, portanto, "a de recepção e/ ou de consumo em vez de interatividade e agenciamento" (Lankshear \& Knobel, 2007: 16).

Já na Web 2.0, opera-se sob uma outra lógica: a da participação, a da colaboração, a da inteligência coletiva e a da possibilidade de intensificação das relações sociais nas wikis, espaços de afinidades, fan-fiction etc. Ao associar esses diferentes tipos de Webs a momentos sociohistóricos mais amplos, Knobel \& Lankshear (2007) dizem que cada um desses tipos de Web se refere a modos diferentes de pensar e agir ou a uma atitude mental (mindset) de uma época. A Web 1.0 se refere ao mindset 1, envolvendo uma tecnologização sofisticada, mas não altera os modos de pensar e agir nas redes. Knobel \& Lankshear (2007: 10) indicam que o mundo da tecnologia do mindset 1 é

\footnotetext{
"o mesmo mundo econômico, cultural, social que se desenvolveu por toda a modernidade, na qual as coisas eram feitas por meio de rotinas que se baseavam em pressuposições antigas sobre os corpos, materiais, propriedade e formas de possuir coisas, técnicas e princípios industriais, textos físicos, [e] interações face a face".
}

Por outro lado, na Web 2.0. o mindset é orientado por outras formas de agir e pensar que caracterizam a vida contemporânea, como fruto do "desenvolvimento de novas tecnologias da internet e novos modos de fazer coisas e novos modos de ser [meus itálicos] que são possibilitados por essas tecnologias" (Lankshear \& Knobel, 2007: 10). Assim, as mudanças que acompanhamos no mundo são pautadas por ações diferentes que as tecnologias que caracterizam o mindset 2.0 tornam possíveis (Davies, J \& Merchant, 2009). Nesse mundo, o que conta é a possibilidade de compartilhar a informação de dividi-la com outros e, assim fazendo, ampliar as redes de relações sociais. Isso é o que explica a compulsão incessante de passar a informação para outros, em vez de guardá-la para si mesmo, um movimento típico dos nossos tempos. Tal movimento é o que orienta o mindset 2.0 ao 
passo que colabora para que possamos imaginar outras possibilidades de interagir, aprender, ser, agir, pensando em conjunto ou em colaboração com outros.

Tais possibilidades são potencialmente ilimitadas, como acima apontado. Assim, essa não é a sociedade da informação, mas sim a sociedade da intensificação das relações sociais (Schrage, 2001). A autoria deixa de ser menos importante, já que o que conta é a ação colaborativa em que a autoria fica dispersa ou é apagada: um processo que explica a inteligência coletiva em um espaço de afinidades comuns que orientam as ações dos participantes, ou seja, seus propósitos de ações comuns. Tal processo também nos conduz ao mundo de práticas de remixagens / hibridizações de artefatos culturais, textos, músicas, vídeos etc., construídos por outros, o que leva a produção do novo (um novo texto, novos modos de ser, de agir etc.) (Lankshear \& Knobel, 2007). Nesse mundo não há, portanto, a separação entre produtor e consumidor, já que não vivemos mais sob a ordem de um especialista / autor que produz o que um outro irá consumir. A ordem é a do que Gómez Cruz (2008: 202) denomina de a do "prosumidor", "um conceito que se origina nos anos 80, no discurso de Alvin Toffler" e que qualifica o usuário da Web 2.0.

Ao desprezar, dessa forma, o lugar sagrado do produtor/autor e ao prestigiar a ação conjunta em espaços de afinidades, qualquer usuário na Web 2.0 pode, potencialmente, operar do ponto de vista pragmático com a possibilidade de agenciamento, de atuar politicamente e de ser, portanto, um ativista político, ou seja, de defender seus pontos de vistas ou de agir no mundo para transformá-lo de uma forma ilimitada e ampliada. Do ponto de vista epistemológico, a compreensão teórica do mindset da web 2.0 como ações de pessoas em conjunto em espaços entendidos como práticas sociais de letramentos torna possível qualificá-los como lugares onde a vida social pode ser construída, criticada, transformada, reinventada ou, em última análise, transgredida. Desse modo, é possível dizer, seguindo O'Reilly (2005) que 'a Web 2.0 não é uma tecnologia mas uma atitude’.

\section{ATIVISMO POLÍTICO NA WEB 2.0}

Em sociedades como as nossas que têm sido caracterizadas como de grande reflexividade por causa dos processos de hipersemiotização já mencionados anteriormente, em que a política tem sido substituída ou acompanhada e, em muitos casos orientada, por sub-políticas, torna-se essencial estudar as práticas sociais dos novos letramentos digitais como lugares que dão lugar a tais sub-políticas por meio do ativismo político. Essa visão leva Beck (1995: 29) a indicar que as sub-políticas apagaram a política, provocando "um renascimento não-institucional do político" (:28), "no qual o sujeito individual retorna às instituições da sociedade"'(:28).

A necessidade de estudar os novos letramentos digitais de tal perspectiva pode ser explicada, primeiramente, pelo fato de serem caracterizados como típicos do mindset 2.0 , no qual o participante se transforma em um "prosumidor", ou seja, envolve-se na construção do discurso com outros. E em segundo lugar, por que nas redes sociais da Web 2.0, os participantes têm colaborado na construção de sub-políticas, por meio das quais os indivíduos têm anunciado os temas que têm feito ultrapassar dogmas e narrativas cristalizados. Esses temas nas telas dos computadores adentram as nossas casas e são 
bem diferentes da política oficial. Tal visão é importante, já que "os temas do futuro, que agora estão na boca de todos, não se originaram na boca dos governantes ou nas brigas do parlamento" (Beck, 1995: 31). Inicialmente, apareceram nos movimentos sociais e agora se multiplicaram nas redes sociais, que podem ser compreendidos como um espaço para escapar da política oficial ou da política do senso comum ${ }^{4}$.

Os temas da política oficial, em geral, não anunciam o futuro, pautando-se por confirmar os padrões tradicionais, notadamente com base em ideias fundamentalistas sobre as práticas sociais e em processos de homegeneização da vida social, que levam a temer a alteridade: um processo que não faz sentido do ponto de vista ético diante da grande heterogeneização que nossas vidas sociais enfrentam. Ainda que muitos desses temas de sub-políticas tenham surgido bem antes da Web 2.0, como, por exemplo, os movimentos sociais dos anos 70 de liberação da sexualidade, das mulheres e de anti-racismos, a Multidão a que se tem acesso na Web 2.0, em formas de construção, discussão, negociação, contestação de sentidos nas redes sociais, amplia sobremodo a difusão de tais sub-políticas assim como de outras. É fato, porém, que no Brasil tais movimentos sociais só se tornaram mais amplamente discutidos a partir dos anos 90, com o fim da ditadura militar.

As sociedades de fluxos (Appadurai, 2001), do mundo em descontrole (Giddens, 2000) e de vertigens (Fridman, 2000 ) em que vivemos são um convite à politização da vida social. Se as fronteiras caem, se o mundo está desordenado, e se ele continuamente nos causa vertigens, o espaço para um novo panorama para nossas narrativas de vida e sobre como podemos alterá-las é inaugurado. Um mundo de incertezas sobre quem somos ou pelo menos um mundo de possibilidades em relação a quem podemos ser passa a ser a inspiração para muitos que vêem os limites que orientavam nossas vidas no passado serem questionados ou, pelo menos, aventados como temas que devem ser politizados.

Tópicos para disputas, para questionamentos e para desconstruir as velhas narrativas que nos trouxeram até aqui não faltam. Em tal mundo, a politização de nossas vidas, por meio da defesa e recusa de percepções e de visões do mundo é acirrada. Os movimentos sociais, em alguns casos no Brasil dos últimos anos, têm sido encampados pelas políticas oficiais, com avanços notáveis (por exemplo, uma secretaria de governo que trata dos direitos das mulheres, o programa Brasil sem Homofobia, as políticas de quotas raciais nas universidades etc.). No entanto, pouco tem sido dito em relação a como tais movimentos sociais (entre outros) têm-se utilizado dos novos letramentos digitais como lugar de ativismo político, já que a tecnologia como lugar de política tem sido tradicionalmente apagada, conforme já indicado.

Especialmente, deve-se ressaltar a possibilidade de anonimato que os participantes dos novos letramentos digitais têm, facilitando o tratamento de temas tabus como sexualidade e gênero nem sempre enfrentados sem esforço no face a face. Nos espaços de afinidades, por exemplo, típicos da Web 2.0, a politização da sexualidade e do gênero toma uma outra dimensão uma vez que a participação é aberta a todos, o que torna possível o engajamento mais democrático em tal temática assim como a negociação, a contestação e a disputa na construção dos significados. Para ter acesso a tais discursos sobre sexualidade

\footnotetext{
${ }^{4}$ Isso não quer dizer, por outro lado, que todos os discursos que circulam nas redes sociais devam ser secundados. Há princípios éticos, relativos, em última análise, a discursos que causam sofrimento humano, que devem embasar as escolhas de significados que fazemos.
} 
e gênero, este trabalho enfoca o ativismo político em um blog e no orkut, entendendo-os como práticas sociais de letramentos digitais, ao estudar as trocas interacionais em desenvolvimento ali, de modo a tornar visível o que conta como letramento em tais práticas sociais e assim compreender os discursos que orientam o ativismo político nesses espaços.

$\mathrm{O}$ que baliza meu interesse em questões relativas ao ativismo político nos novos letramentos digitais é a necessidade imperiosa dos nossos tempos de prestigiar significados que possam apresentar alternativas para as nossas práticas sociais. Compartilho, assim, da visão de Boaventura Santos (2006) de que o discurso das Ciências Sociais e Humanas (portanto, da Lingüística Aplicada) é um discurso em competição com outros sobre a vida social e como tal pode produzir narrativas que conservem o presente ou que o reinventem. Fazer pesquisa pode ser visto como um modo de re-inventar a vida social, o que inclui a reinvenção de formas de produzir conhecimento assim como formas de vida já que a pesquisa é uma maneira de construir a vida social ao passo que tenta compreendê-la (Boaventura Santos, 2008). Atuo em uma Lingüística Aplicada especialmente interessada na produção de "uma narrativa que mude o presente", como diz o crítico cultural Venn (2000: 2), na tradição de estudos pós-coloniais.

\section{INSTRUMENTAL ANALÍTICO: UMA TEORIA DA ESTRUTURA DE PARTICIPAÇÃO NO DIÁLOGO}

Antes de passar ao estudo de dois espaços de afinidades (um blog e um no orkut, i.e., dois tipos de novos letramentos digitais) como lugares de ativismo político sobre sexualidade e gênero, quero discutir brevemente o instrumental analítico que orientará o estudo. Compreendendo a conversa escrita nos espaços de afinidades como ferramenta de mediação na construção social dos significados, como já indicado acima, e também como um modo de ter acesso ao que conta como letramento nessas duas práticas sociais, ao estudar as contribuições interacionais dos participantes, recorro ao estudo de Linell (1990) sobre o poder na dinâmica do diálogo oral (que adapto aqui para o diálogo escrito) ou sobre uma teoria da estrutura de participação no diálogo.

Nas palavras de Linell (1990: 147),

\footnotetext{
"o poder na dinâmica do diálogo entendido como o jogo interacional das iniciativas $e$ respostas dos participantes [itálicos no original], separadamente do próprio discurso, gera uma teia de relações sociais, compromissos e responsabilidades, e possivelmente também perspectivas, atitudes e conhecimentos compartilhados".
}

Esse jogo interacional, portanto, por sua própria natureza, ou seja, por ser construído com base em uma teia de relações sociais e no que é compartilhado entre os participantes, faz emergir padrões de simetria e assimetria, que são intrínsecos à construção social do diálogo e dos significados. Isso não quer dizer, por outro lado, que os significados sejam sempre novos, já que os participantes se baseiam em tradições socioculturais que compartilham e que são sempre recuperadas (Linell, 1990). Tal posição significa que há em operação, em qualquer evento interacional, tanto aspectos micros da organização discursiva (aqui conversas escritas onde contra-discursos podem surgir) e aspectos macro 
socioculturais e históricos (aqui especificamente, em nossos tempos, como já indicado anteriormente: acesso aos significados da Multidão ou aos discursos dobre sexualidade e gênero a que se pode ter acesso hoje). Assim, o significado é sempre situado com base em quem são os interlocutores (em suas iniciativas e respostas, que indicam suas compreensões do que está ocorrendo na interação) e nas práticas socioculturais e históricas nas quais operam.

Linell (1990) sugere quatro categorias ou dimensões diferentes para estudar o domínio e as assimetrias no diálogo que podem ser operacionalizadas, neste trabalho, para estudar a conversa escrita nos espaços de afinidades de ativismo político. A primeira se refere à quantidade de fala (aqui texto escrito, muitas vezes oralizado): quem domina é, portanto, quem mais fala, ou seja, trata-se de domínio quantitativo. A segunda tem a ver com domínio semântico, que dá conta do participante que mais introduz tópicos interacionais ${ }^{5}$, conseguindo mantê-los na discussão. A terceira explica o que chama de domínio interacional, ou seja, aplica-se ao participante que mais contribui com iniciativas interacionais, contribuindo para o desenvolvimento da conversa (movimentos direcionais, controladores e inibidores da interação). O participante secundário, ao contrário, permite que sua fala seja controlada. E a quarta se refere ao domínio estratégico que explica o participante que não fala muito, i.e., não faz muitas iniciativas, mas suas contribuições são relevantes do ponto de vista estratégico em relação ao ponto que está sendo discutido.

\title{
5. ANÁLISE DE DOIS ESPAÇOS DE AFINIDADES COMO LUGAR DE ATIVISMO POLÍTICO: UM BLOG E UMA PÁGINA NO ORKUT
}

\begin{abstract}
"Uma ideia de espaço produzido socialmente, que encontra no social a primeira e mais importante de suas características, se ajusta perfeitamente a esta ideia de ciberespaço. O fato de a ênfase se colocar nas dinâmicas sociais significa que, antes de tudo, se trata de um lugar [itálico no original] para a ação social, de baixo a cima, um ambiente de rede transitório e para a construção de identidades líquidas" (Mayans i Planells, 2008: 114).
\end{abstract}

\section{$\mathrm{O} B \log ^{6}$}

O blog que é analisado a seguir se caracteriza por fazer ativismo político em defesa dos direitos LGBTs (de lésbicas, gays, bissexuais, travestis e transexuais). Após descrever o objetivo do blog, no dia 5/7/2009 o autor postou uma discussão com base no que foi publicado na revista Superinteressante (veja a capa da

\footnotetext{
${ }^{5}$ Seguindo Brown \& Yule (1986), entendo que o tópico interacional é determinado pelo que chamam de "arcabouço do tópico", ou seja, "aqueles aspectos do contexto que são diretamente refletidos no texto, e que precisam ser trazidos à tona para interpretar o texto [tais aspectos] constituem o arcabouço contextual dentro do qual o tópico é constituído, ou seja, o arcabouço do tópico” (: 75). Essa questão "envolve uma análise constante sobre o porquê o falante disse o que disse em uma situação particular de conversa” (: 77).

${ }^{6} \mathrm{Um}$ blog (contração de web $\log$ ) é um site que pode ser atualizado rapidamente pelo autor, com artigos, imagens etc., sobre um determinado tema. Muitos funcionam como um tipo de diário. Outros deixam espaços para visitantes interagirem por meio de postagens, operando também, portanto, como uma comunidade de afinidade sobre um tópico. É o caso do blog estudado neste trabalho. Os textos aparecem aqui da mesma forma em que foram postados no blog (http://pt.wikipedia.org/wiki/Blog).
} 
revista abaixo), que apontou que 37 direitos são negados aos cidadãos LGBTs, já que legalmente não podem se casar. $\mathrm{O}$ autor elenca, porém, 78 direitos negados aos casais formados por gays e por lésbicas, indicando, portanto, que a revista exclui muitos outros direitos. Ilustra ainda o texto introdutório como uma imagem de uma estátua que simboliza a justiça. Abaixo, segue o blog. Note que por questão de espaço editei a lista de direitos, marcadas abaixo com o símbolo [...]. O leitor pode consultá-la no próprio blog (http://carlosalexlima.blogspot.com/ 2009/07/pelo-menos-78-direitos-sao-negados.html (acessado em 7/10/2010) ${ }^{7}$.

\section{Direitos Fundamentais LGBT ${ }^{8}$}

O presente blog se propõe a reflexão sobre os Direitos Humanos nas suas mais diversas manifestações e algumas amenidades.

Este Blog

\section{domingo, 5 de julho de 2009}
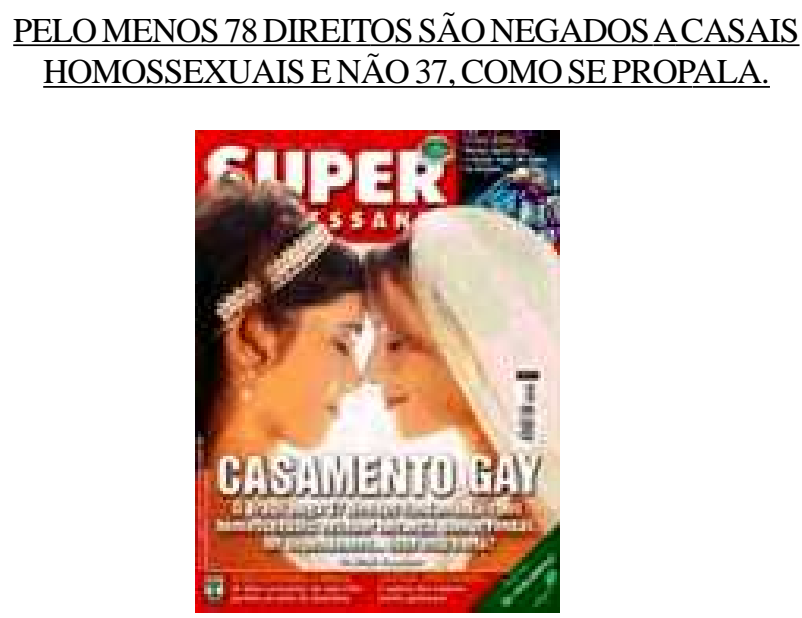

Foi publicado pela Revista SUPERINTERESSANTE, edição 202, de julho de 2004, uma relação fornecida pelo jornalista Sérgio Gwercman, constando que pelo menos 37 direitos que são negados a casais homossexuais. A matéria foi longa e extremamente bem realizada, tendo na capa uma foto de duas mulheres, aparentemente numa celebração de união, com a seguinte chamada: "CASAMENTO GAY”.

${ }^{7}$ Tanto nas partes de blog como nas da comunidade do Orkut, transcritos aqui, apaguei as fotos dos participantes e alterei seus nomes para preservar suas identidades.

${ }^{8}$ Sou grato a Rodrigo Borba (UFRJ) e a Victor Schultz (UFRJ), meus orientados no Programa Interdisciplinar de Pós-graduação em Linguística Aplicada da UFRJ, pelas indicações do material analisado aqui. 
Essa relação até hoje vem sendo repetida em vários segmentos LGBTs e até alguns políticos integrantes do Poder Legislativo a reproduzem, razão pela qual ora se transcreve:

"37 razões para dizer sim

Você pode não pensar neles, mas ao casar ganhamos algumas dezenas de benefícios. Confira a lista dos direitos aos quais casais gays não têm acesso

[....]

A par do mérito da lista divulgada, na verdade, a título meramente exemplificativo, sem pesquisar as inúmeras leis existentes, PODERÍAMOS ULTRAPASSAR NA RELAÇÃO MAIS DO DOBRO DESTE NÚMERO DE DIREITOS NEGADOS AOS CASAIS HOMOSSEXUAIS, senão vejamos:

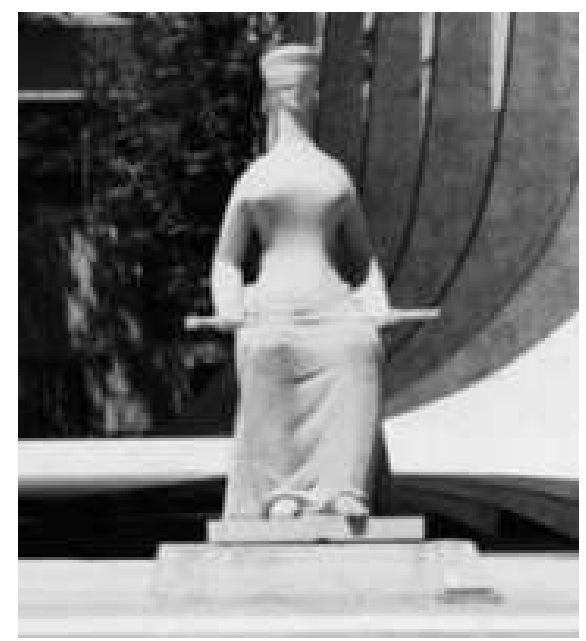

[....]

Tampouco, ressalvo, se encerram nestes 78 itens relacionados os direitos negados aos casais homossexuais, pois os acréscimos aqueles 37 direitos iniciais decorreram de uma rápida e muito superficial observância junto a algumas leis federais, devendo ainda muitas outras leis serem verificadas.

João Silva

Postado por João Silva Pas $\underline{\text { 05:30 }}$

8 comentários:

Renata disse...

Parabéns pela iniciativa e qualidade! 
LOPES - Os novos letramentos digitais...

Renata

5 de julho de 2009 11:48

Creuza disse...

Querido João,

Excelente o seu artigo sobre os direitos negados aos LGBTs!!!

Beijos,

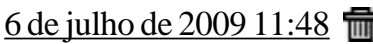

Anônimo disse...

70\% dos direitos é para "mamar" nas tetas do governo

28 de agosto de 2009 02:23 而

VANESSA disse...

Acredito que deus fez a mulher para completar o homem e vice versa não discrimino ninguém mas o tanto o homem quanto a mulher foram feitos para viver um com o outro pois, o fruto da carne é o pecado, e esse tipo de coisa são demonios tentando distupar o verdadeiro sentido da vida deus abomina esse tipo de coisa disculpa essa é a realidade!!!!

\section{3 de outubro de 2009 11:27 而}

Elvira disse...

Se não bastasse todos os preconceitos que temos que vencer a cada dia, ainda nos são negados inúmeros direitos civis, como se não pagássemos nossos impostos como qualquer outro cidadão.

Parabéns pelo blog!

9 de novembro de 2009 11:14

João Silva disse... 
Vanessa,

Você é bem-vinda aqui, mas o presente blog não se destina a discutir sobre as crenças religiosos, mas DIREITOS FUNDAMENTAIS garantidos na Constituição Federal, que é laica.

Não tenho que desculpá-la de nada, apenas lamentar e respeitá-la, esperando que você também aprenda a respeitar aqueles que pensam diferente de você.

24 de janeiro de 201022:22 感

Jairzinho disse...

Jair

olha realmente é lamentável, e o pior de tudo é que quando vamos reivindicar os nossos direitos somos obrigados ouvir cometários como de nossa colega Vanessa, que acredito eu não percebeu o sentido da matéria.

19 de fevereiro de 2010 12:32 而

Diogo disse...

Lamentável o comentário da Vanessa, o minímo que posso fazer é respeitar a opinião de uma pessoa assim.

Muito bom o post João. Em breve chegaremos lá.

Até +

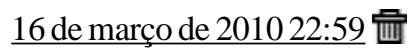

\section{$\underline{\text { Postar um comentário }}$}

Links para esta postagem

Sabia dessa? 78 direitos são negados a casais homoafetivos 而

Inicialmente foram levantados, pelas advogadas Dr $^{\mathrm{a}} \mathrm{s}$ Maria Berenice e Miriam Correa, 37 direitos negados aos casais homossexuais, publicados na Revista Superinteressante em 2004. Posteriormente, o também advogado Dr. ...

Postado por Janaina Rochido às 21 de março de 2010 22:00

A conversa é iniciada pelos comentários de Renata e Creuza que se posicionam de acordo com a proposta do blog, ou seja, parabenizam o autor pelo blog e pela posição que toma. Elas se alinham, portanto, aos significados mobilizados por João. No entanto, a terceira iniciativa de Anônimo vem quebrar a defesa dos direitos LGBTs, ou seja, vem questionar a proposta do ativista político. Explicitamente, Anônimo discorda da lista apresentada, indicando que a posição do dono do blog (João) se trata de fato de um modo 
de tomar dinheiro do governo. Parece concordar que somente $30 \%$ dos direitos seriam aceitáveis. Anônimo tenta, assim, inibir o tópico interacional. Contudo, João não se manifesta em relação à iniciativa de Anônimo. Tal fato pode ser compreendido como uma tentativa de manter o domínio estratégico na conversa por parte de João ao ignorar uma contribuição interacional discordante.

Mas eis que quase dois meses após a contribuição de Anônimo, surge uma outra colaboração que, apelando ao discurso religioso (notem o uso de itens lexicais que remetem a tal discurso: Deus, demônios, carne, pecado etc.), vem contrariar a politização dos direitos LGBTs proposta por João: novamente trata-se de uma iniciativa inibidora do tópico interacional. A contribuição seguinte de Elvira também usa do mesmo recurso de domínio estratégico usado por João, já que igualmente ignora as iniciativas de Anônimo e de Vanessa e se refere à proposta de João com a qual concorda. Mas finalmente três meses após a provocação de Vanessa, João resolve respondê-la. Mantendo o domínio estratégico, João dá as boas-vindas à Vanessa ao blog, indica que não tem por que desculpá-la pela discordância, apontando que o espaço não era para o discurso religioso mas para a discussão dos direitos dos cidadãos. Termina por sugerir que ela aprenda a respeitar discursos diferenciados dos dela. É notável como João na posição de ativista político continua a exercer o domínio estratégico encaminhando a discussão para seus interesses ao mesmo tempo em que também estrategicamente não destrata Vanessa.

As duas últimas iniciativas são de Jair e de Diogo que concordam com João e lamentam pela posição que Vanessa tomou; querem, portanto, inibir o movimento interacional de Vanessa. João não se refere a nenhum outro comentário, nem mesmo para agradecer as postagens que o apóiam. O domínio semântico é igualmente exercido por João, já que a maior quantidade de texto é dele. Na posição de ativista político, João domina a interação e o blog do ponto de vista semântico, estratégico e interacional. O que conta como letramento aqui é agir interacionalmente na direção de discutir, concordar, ou negar a posição do ativista político.

A construção colaborativa do significado, que, nesse caso, ora vai ao encontro da posição de autoria de João como dono do blog ora a desarticula, torna o significado fluido, um lugar de disputa interacional com base nas várias contribuições que surgem. Isso exemplifica também como nas redes sociais estamos, de modo mais exacerbado, diante de significados inesperados, desestruturadores e inovadores, que a força discursiva da Multidão faz circular, possibilitando a reinvenção social, nesse caso em relação a vidas cujas expressões do desejo sexual são consideradas abjetas.

\section{Um espaço de afinidades no Orkut ${ }^{9}$}

Trata-se de um espaço centrado na questão do feminismo e tem, portanto, o objetivo de fazer ativismo político em relação à posição das mulheres na sociedade, especificamente, centra-se na luta pela igualdade entre mulheres e homens, como se pode ler na descrição da página do Orkut abaixo. Novamente aqui, editei o texto por razões de espaço, mas a página

${ }^{9}$ O Orkut é uma rede social construída por Orkut Büyükkokten para incentivar as relações sociais entre as pessoas. A maioria dos usuários está no Brasil e na Índia. No Brasil o Orkut é a rede social favorita (http://pt.wikipedia.org/wiki/Orkut, acessado em 7/10/10). 
pode ser acessada em. http://www.orkut.com/Main\#Community?cmm=412404 (7/10/2010). Entre os tópicos ${ }^{10}$ postados pelos participantes, escolhi para análise o seguinte "E nós somos as vagabundas novamente", já que tinha o maior número de postagens então. Este tópico foi sugerido por Alda e foi motivado por uma matéria jornalística que relata o fato de um homem ter sido julgado inocente, após ter sido condenado como culpado anteriormente, por ter mantido relações sexuais com três adolescentes, as quais, como ficou provado, frequentavam festas nas quais havia prostituição. Por razões de espaço, a análise enfoca, principalmente, a primeira página de um total de 115 postagens.

\section{Feminismo e Feministas $\sigma^{\prime \prime}=\varnothing$}

$\underline{\text { Início }}>\underline{\text { Comunidades }}>\underline{\text { Culturas e Comunidade }}>$ Feminismo e Feministas $\sigma^{n}=\emptyset$ descrição:

O FEMINISMO é um movimento político que busca a desnaturalização e superação das relações hierárquicas entre mulheres e homens, lutando pela IGUALDADE SOCIAL, POLÍTICA, CULTURAL e ECONÔMICA entre os sexos. Formado e motivado primeiramente a partir de experiências da mulher, o movimento apresenta uma crítica à estrutura patriarcal da sociedade que serve de base ao machismo.

Ao contrário do que muitos pensam, o feminismo é um movimento social pela IGUALDADE entre os gêneros humanos, e NÃO acredita que as mulheres sejam superiores aos homens!

REGRAS da comunidade:

http://www.orkut.com/CommMsgs.aspx?cmm=412404\&tid=2478969629779996990

Nós queremos IGUALDADE!

http://pt.wikipedia.org/wiki/Feminismo

NÃO somos sexistas!!!

http://pt.wikipedia.org/wiki/Femismo

Esta comunidade foi incluída entre as 100 selecionadas pela reportagem "O outro lado da força: comunidades 'do bem' reúnem 1 milhão":

http://verdesmares.globo.com/v3/canais/noticias.asp?codigo $=140248 \&$ modulo $=840$

idioma:

Português (Brasil)

${ }^{10}$ Tópico aqui se refere à lista de assuntos sugeridos pelos participantes na própria comunidade. Veja a nota 2 acima em relação à teorização usada na análise em relação ao tópico interacional. 
LOPES — Os novos letramentos digitais...

categoria:

$\underline{\text { Culturas e Comunidade }}$

dono:

Lina

moderadores:

$\underline{\text { Janilson, }} \underline{\text { Neusa, Frida }}$

tipo:

moderada

privacidade do conteúdo:

aberta para não-membros

local:

Brasil

criado em:

12 de setembro de 2004

membros:

12.851

\section{E nós somos as vagabundas novamente}

$\underline{\text { Início }}>\underline{\text { Comunidades }}>\underline{\text { Culturas e Comunidade }}>\underline{\text { Feminismo e Feministas }} 0$ Fórum: > Mensagens

primeira | < anterior | próxima > | última mostrando 1-10 de 115

28 set

Alda

E nós somos as vagabundas novamente 
Tô indignada

http://g1.globo.com/sao-paulo/noticia/2010/09/justica-absolve-homem-acusado-de-fazer$\underline{\text { sexo-com-adolescentes-em-sp.html }}$

28 set

$\stackrel{\sim}{\sim}$ Maria오

lamentavel

tinham que castrar um velho nojento desses

28 set

3 Janaína, ${ }^{2}$

O juiz deve ser da mesma laia....

ta cheio de pedófilo no meio judiciário....

28 set

Betina

E muita gente deve ter aplaudido.

Tenho penado pra tirar da minha mãe a ideia de que "ah, mas essas menininhas de hoje também não são fáceis".

Que nojo.

28 set

$\underline{\text { Deise }}$

esse cara deve considerar correto o comportamento do safado... que será de nós se não houver mais mulheres nos representando nos setores de poder?!

28 set

$\underline{\text { Eliana }}$

A questão é essa... Muita gente que está lá pra julgar deve fazer as mesmas coisas ou até pior do que aqueles que eles estão julgando, então não vão condenar alguém que faz algo que eles mesmos aprovam por trás. Tem muita coisa que é de interesse pessoal deles mesmo, imagino... 
Se o juiz, como parece, partiu da premisso que se relacionar com menores de 18 (e maiores de 14) for crime, e utilizou dessa justificativa (frequentar festas ou usar roupas provocantes), creio que ele agiu de forma errada.

Porém, se o caso fosse outro. $\mathrm{O}$ do Juiz não partir do principio que entre as idades citadas não exista o crime, pois, na concepção dele, uma moça com quinze a dezessete anos que queira ter um relacionamento com um homem mais velho, pode ter, uma vez que não é necessariamente uma pessoa que deva ser protegida. Assim como o desdejo de muitos dos meninos (e isso me lembro bem), era ter algo com uma mulher mais experiente. Além disso, entre os homossexuais masculinos, isso é uma prática comum.

Neste caso, creio que existiria uma coerencia na postura dele, baseado no principio de tratar os generos da mesma forma.

Notem que a idade é a partir dos 15 anos, pois, me corrijam se tiver errado, é a idade que é permitida por lei.

28 set

Betina

Eu acho desnecessário mencionar que "essa prática é comum entre homossexuais". Isso não legitima nada. E outra, essa prática é bem comum entre heterossexuais também.

Agora minha opinião, francamente. Meninas de quinze anos na maioria das vezes não tem maturidade de mulher ainda não. E falo isso por conviver com elas na escola.

A lei pode não prever punição porque elas passaram dos catorze, mas eu tenho nojo de cara mais velho que se aproveita da imaturidade delas. Pra mim não são diferentes de quem estupra criança de dez.

28 set

$\underline{\operatorname{Marcos}}$

Foquei os homossexuais masculinos e os meninos de 15 anos que são atraidos por mulheres mais experientes, por ser um grupo que conheço. É uma curiosidade comum a ambos os grupos.

28 set

Betina 
E mesmo que na lei não esteja previsto que se presuma estupro em relações sexuais de maiores de idade com menores a partir dos quinze, o juíz não tem o direito de usar a conduta das vítimas para inocentar o sujeito como ele fez. Isso é inaceitável em qualquer situação.

Agora uma pergunta. No texto mencionam que elas têm mais de quinze? Eu não achei nada lá sobre idade delas. Até queria saber.

primeira $\mid$ <anterior $\mid$ próxima $>$ última

denunciar spam

responder

«voltar aos tópicos

\section{tecnologia do

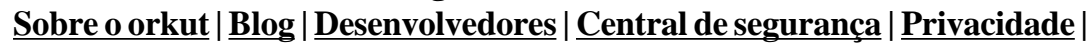 Termos de uso $\mid$ Publicidade $\mid$ Ajuda}

O tópico de discussão ("E nós somos as vagabundas novamente") é sugerido por Alda, que além de incluir um link para a matéria jornalística, constrói a primeira iniciativa interacional, indicando sua indignação em relação à matéria, como, de fato, por ser uma página feminista de ativismo político, não poderia ser diferente. Note-se que nem a dona da página nem nenhum dos moderadores aparecem nas primeiras postagens. Maria se alinha ao posicionamento de Alda, que nas 115 postagens só tem uma outra iniciativa interacional, quando indica que o tópico da discussão tinha se desvirtuado da questão referente a como as mulheres são tratadas como vagabundas. Embora não tenha participado da discussão, ela, no entanto, exerce domínio estratégico na postagem 96 para que os participantes não se afastem do tópico que ela sugeriu: "Concordo com a Linda, cada caso um caso, lógico que existem absurdos como uma menina de 12 anos engravidar de uma cara de 30, mas noto que o tema do tópico acabou se desviando, pois o post se trata de prostituição, abuso e não uma relação "normal'". Tudo leva a crer que Alda monitorou a interação, exercendo domínio estratégico quando necessário.

As iniciativas interacionais seguintes àquela inaugural de Alda (de Maria, Janaína, Betina, Deise, e Eliana) se alinham ao tópico de discussão, acrescentando visões que vão ao encontro do ponto levantado por Alda. Assim, pode-se dizer que, embora Alda não tenha introduzido outros tópicos interacionais nessa primeira página e, de fato, nas outras, ela exerce um certo domínio semântico, uma vez que as participantes até aqui operam dentro do tópico que ela sugeriu. No entanto, o movimento interacional de Marcos é inibidor do desenvolvimento da interação uma vez que problematiza os posicionamentos dos participantes que o precederam. Marcos introduz um tópico interacional que, pela primeira vez, vai provocar desvio do tópico sugerido por Alda, a questão relativa ao desejo sexual de jovens por homens e mulheres mais velhas: um tópico interacional que vai acompanhar a discussão toda como é, de fato, evidenciado no movimento interacional de Alda na postagem 96, mencionada acima. Assim, nesse espaço de afinidades há uma disputa pelo domínio interacional. 
Marcos aponta que provavelmente o juiz decidiu com base na compreensão de que uma menina de 15 anos pode ter desejo sexual por homens mais velhos. Para corroborar seu argumento, exemplifica com pessoas de seu relacionamento, com a finalidade de atribuir valor epistêmico a sua posição. Em outras palavras, Marcos indica que conhece meninos homossexuais que apreciam fazer sexo com homens mais velhos assim como meninos heterossexuais que gostam de sexo com mulheres mais velhas. Dessa forma, argumenta que o juiz teria sido coerente ao tratar os gêneros igualmente. No entanto, Betina, a seguir, discorda de Marcos e tenta exercer o domínio interacional do tópico, ao apontar que os argumentos de Marcos não dão legitimidade à decisão do juiz, ao citar meninos homossexuais e heterossexuais.

O movimento interacional de Betina pode ser identificado como controlador do tópico. Marcos novamente justifica seu movimento interacional pelo valor epistêmico que tem: "um grupo que conheço" Betina volta, a seguir, ao tópico interacional sugerido por Alda inicialmente: as mulheres são usadas pelo juiz para inocentar o acusado, já que eram prostitutas. $\mathrm{O}$ que conta como letramento nestes espaço de afinidades é, na verdade, agir interacionalmente na disputa pelo tópico interacional: a posição feminista acusa o juiz enquanto que a de Marcos relativiza tal posição ao considerar o desejo sexual das jovens por homens mais velhos.

Igualmente, como no caso do blog, a construção conjunta do significado nessa página do Orkut, complexifica a posição de autoria, mostrando como os significados na Web 2.0 são mais participativos e menos autorais. Ao mesmo tempo, a disputa interacional nesse espaço de afinidade nos conduz a posicionamentos questionadores do ativismo político feminista ao reverter visões cristalizadas sobre o que é a construção legítima do desejo sexual, associado a uma determinada faixa etária. Novamente, estamos frente a frente aos discursos inesperados e diferenciados da Multidão, os quais são típicos das redes sociais.

\section{FINALIZANDO: AO ENCONTRO DAS RELAÇÕES / DINÂMICAS SOCIAIS EMMEIOA MULTIDÃO}

O que me parece essencial ressaltar, ao concluir este estudo, se refere a como a vida nas práticas sociais dos novos letramentos digitais, ao nos fazer ir ao encontro da Multidão, nos oferece uma gama de possibilidades de redescrições / questionamentos sobre quem somos ao passo que amplia nossas relações e reinvenções sociais, como as análises acima destacaram. Além disso, tais letramentos podem funcionar também como um lugar no qual o ativismo político, da mesma forma que na ágora grega da Antiguidade Clássica assim como nos velhos moinhos, tem mais espaços (agora infinitamente expandidos) de agenciamento, de transgressão de narrativas dadas ou de construção de pensamentos inovadores sobre a vida social como pode também se defrontar com discursos questionadores: um traço muitas vezes favorecido pelo anonimato nas redes.

Esses movimentos discursivos são possibilitados pelos modos por meio dos quais, como tentei argumentar acima, os participantes de tais letramentos se organizam como participantes de espaços de afinidades do mindset 2.0 na construção de uma inteligência coletiva como cidadãos e prosumidores. A politização da vida social está agora mobilizada 
continuamente nesses novos letramentos digitais e nos usos variados e transgressivos que as pessoas quiserem deles fazer, da mesma forma que está também facilmente acessível no teclado do computador. Assim, como nos alerta Mayans i Planells (2008: 114-115),

\begin{abstract}
"o hardware - quer seja informático quer seja urbano - não determina a sociabilidade que em seus espaços se desenvolve. Praças e espaços públicos são constantemente objeto de usos inesperados, e inclusive subversivos em relação aos seus usos primeiros. $\mathrm{O}$ mesmo ocorre com a tecnologia e o ciberespaço, redefinidos e reformulados constantemente por seus usuários / cidadãos / prosumidores. A relevância política dessa visão é muito significativa já que situa o peso principal da ação social - online, offline .... que importa? - nas dinâmicas sociais, cujas capacidades foram reforçadas e empoderadas pela tecnologia."
\end{abstract}

Está, dessa forma, em nossas mãos a possibilidade de ensaiar o futuro, dando usos políticos aos novos letramentos digitais de modo a construir um mundo de ações sociais pautadas na justiça social e na ética: duas questões cruciais em nossos tempos. As análises dos espaços de afinidades acima parecem sugerir que os novos letramentos digitais podem se constituir como lugares de linhas de fuga da política tradicional assim como do senso comum, por meio das sub-políticas que fazem circular, ao mesmo tempo em que colaboram para a construção de futuros alternativos.

\title{
REFERÊNCIAS BIBLIOGRÁFICAS
}

APPADURAI, A. (2001). Grassroots globalization and the research imagination. In: APPADURAI, A. (org.) Globalization. Londres: Duke University Press.

BECK, U. (1995). A reinvenção da política: rumo a uma teoria da modernização reflexiva. In: GIDDENS, A.; BECK, U. \& LASH, S. Modernização reflexiva. Trad. Magda Lopes. São Paulo: Editora da UNESP.

BRICE HEATH, S. (1983). Ways with words. Cambridge: Cambridge University Press.

BRICE HEATH, S. \& STREET, B. V. (2008). On ethnography. Approaches to language and literacy research. Nova York: Teachers College Press.

BROWN, B, \& YULE, G. (1986). Discourse analysis. Cambridge: Cambridge University Press.

BUTLER, J. (1999). Gender trouble: feminism and the subversion of identity. Nova York: Routledge.

CLEMINSON, R. \& GORDO, A. (2008). Relaciones tecnosexuales: de los molinos medievales a las páginas de encuentro. In: SÁBADA, I. \& GORDO, A. (orgs.) Cultura digital y movimentos sociales. Madri: Catarata.

COPE, B. \& KALANTZIS, M. (orgs.). (2000). Multiliteracies. literacy, learning and the design of social futures. Londres: Routlegde.

DAVIES, J. \& MERCHANT, G. (2009). Web 2.0 for schools, learning and social participation. Nova York: Peter Lang.

FABRICIO, B. F. \& MOITA LOPES, L. P. (2004). Discursos e vertigens: identidades em xeque em narrativas contemporâneas. Veredas, v. 11, n. 2, p. 11-30. 
FABRÍCIO, B. F. \& MOITA LOPES, L. P. (2010). A dinâmica dos (re-) posicionamentos de sexualidade em práticas de letramento escolar: entre oscilações e desestabilizações sutis. In: MOITA LOPES, L. P. \& BASTOS, L. C. (orgs.) Para além da identidade: fluxos, movimentos e trânsitos. Belo Horizonte: Editora UFMG.

FRIDMAN, L. C. (2000). Vertigens pós-modernas. Configurações institucionais contemporâneas. Rio de Janeiro: Relume Dumará.

GEE, J. (1996). Social linguistics and literacies: ideology in discourses. Londres: Falmer.

GEE, J. (2004). Situated language and learning. A critique of traditional schooling. Nova York: Routlegde.

GINZBURG, C. (1976/1987). O queijo e os vermes. Trad. Maria Betânia Amoroso. São Paulo: Companhia das Letras.

GIDDENS, A. (2000). Mundo em descontrole. Trad. Maria Luiza Borges. Rio de Janeiro: Record.

GÓMEZ CRUZ, E. (2008). Web 2.0: consumidores consumidos, productores preproducidos. In: ARRIAZÚ, R.; BLANCO, R.; CARO, G.; ESTALELLA, A. \& CRUZ, E. G. Intalados en la cresta de la web 2.0.? Cinco autores em busca de la 'big two dot zero. In: SÁBADA, I. \& GORDO, A. (orgs.) Cultura digital y movimentos sociales. Madri: Catarata.

GUIMARÃES, T. F. (2009). A construção performativa do gênero e da sexualidade nas práticas discursivas de uma Lanhouse. Dissertação de Mestrado apresentada ao Programa Interdisciplinar de Pósgraduação em Linguística Aplicada, Universidade Federal do Rio de Janeiro.

HARDT, M. \& NEGRI, A. (2005). Multidão. Guerra e democracia na era do Império. Trad. Clóvis Marques. Rio de Janeiro: Record.

KLEIMAN, A. (1995). Os significados do letramento. Campinas: Mercado de Letras.

KRESS, G. \& van LEEUWEN, T. (2001). Multimodal discourse. Londres: Arnold.

KRESS, G. (2003). Literacy in the new media age. Londres: Routledge.

LANKSHEAR, .C. \& KNOBEL, M. (orgs.). (2008). Digital literacies. Concepts, policies and practices. Nova York: Peter Lang.

LANKSHEAR, C. \& KNOBEL, M. (2007). Sampling the new in new literacies. In: KNOBEL, M. \& LANKSHEAR, C. (orgs.) A new literacies sampler. Nova York: Peter Lang.

LEWIS, C.; ENCISO, P. \& MOJE, E. B. (2007). Reframing sociocultural reserach on literacy. Identity, agency and power. Londres: Lawrence Erlbaum.

LINELL, P. (1990). The power of dialogue dynamics. In: MARKOVÀ, I. \& FOPPA, K. (orgs.) The dynamics of dialogue. Nova York: Harvester Wheatsheaf, 1990.

MAYANS i PLANNELS, J. (2008). En la cibersociedad. Dimensiones analíticas, políticas y sociales del concepto de ciberespacio. In: SÁBADA, I. \& GORDO, A. (orgs.) Cultura digital y movimentos sociales. Madri: Catarata.

MAYBIN, J. \& MOSS, G. (1993). Talk about texts: reading as a social event. Journal of Research on Reading, v. 16, n. 2, p. 138-147. 
MOITA LOPES, L. P. (no prelo). O novo ethos dos letramentos digitais: modos de construir sentido, revolução das relações e performances identitárias fluidas. Programa Interdisciplinar de Pós-Graduação em Linguística Aplicada, UFRJ, mimeo, no prelo.

. (org.) (2006/2008). Por uma lingüística aplicada indisciplinar. São Paulo: Parábola.

. (2002). Identidades fragmentadas. Campinas: Mercado de Letras.

- (2005). A construção do gênero e do letramento na escola: como um tipo de conhecimento gera outro. Investigações Literárias e Linguísticas, v. 17, n. 2, p. 47-68.

. (2008). Sexualidades em sala de aula: discurso, desejo e teoria queer. In: MOREIRA, A. F.; CANDAU, V. M. (orgs.). Multiculturalismo. Diferenças culturais e práticas pedagógicas. Petrópolis: Vozes.

MOITA LOPES, L. P. \& FABRICIO, B. F. (2007). “'Se eu fosse mulher...': performances de gênero e sexualidade em Como Gostais”. In: MOITA LOPES, L. P.; DURÃO, F. A.; ROCHA, R. F. (orgs.). Performances. Rio de Janeiro: Contra Capa.

O'REILLY, T. (2005). What is web 2.0?: design patterns and business models for the next generation of software (http://oreilly.com/web2/archive/what-is-web-20.html) acessado em 4/10/2010).

SÁDABA, I. \& GORDO, A. (2008). Introducción. La tecnologia es política por outros médios. In: SÁBADA, I. \& GORDO, A. (orgs.) Cultura digital y movimentos sociales. Madri: Catarata.

SANTOS, M. (2000). Por uma outra globalização. Rio de Janeiro: Record, 2000.

STREET, B. (1984). Literacy in theory and practice. Cambridge: Cambridge University Press.

SANTOS, B. de S. (2008). Do pós-moderno ao pós-colonial. E para além de um e de outro. Travessias. Centro de Estudos Sociais. Universidade de Coimbra, nos. 6/7, p. 15-36.

SANTOS, B de S. (2006). Renovar la teoria crítica y reinventar la emancipación social. Buenos Aires: Glacso Libros.

SCHRAGE, M. (2009). The relationship revolution. (www.manyworlds.com/ exploreco.aspx?coid=co7300224361756, acessado em 28/1/2009.

VENN, C. (2000). Occidentalism. Modernity and subjectivity. Londres: Sage.

WENGER, E. (1998). Communities of practices. Cambridge: Cambridge University Press.

Recebido: 25/07/2010

Aceito: 25/11/2010 
